\title{
Endoscopic management of the rare situation where a gastric stromal tumor specimen falls into the nasopharynx
}

Endoscopic submucosal excavation (ESE) is a safe and effective minimally invasive method for the treatment of gastrointestinal submucosal tumors, especially for those originating from the muscularis propria [1-3]. Endoloop or vacuum aspiration are traditionally used to collect large specimens, but shedding or damage to specimens sometimes occurs. Here we describe a case in which unusually an endoscopic specimen dropped into the nasopharynx and provide an endoscopic solution for this rare situation ( Video 1).

A 65-year-old man presented to our hospital with an 8-month history of abdominal pain, accompanied by sour regurgitation and belching for 5 months. Physical examination and laboratory studies were unremarkable. Enhanced abdominal computed tomography (CT) scanning indicated a nodular uplift with a clear boundary at the gastric fundus. Esophagogastroduodenoscopy (EGD) revealed a submucosal mass at the gastric fundus ( Fig.1). Endoscopic ultrasonography revealed a mass in the muscularis propria with homogeneous hypoechoic echogenicity (> Fig.2). The patient was clinically diagnosed as having a gastric stromal tumor and he chose to undergo endoscopic treatment.

With the patient under general anesthesia, ESE was performed uneventfully and a solid spherical mass was stripped from the gastric fundus. The specimen was drawn to the front of the gastroscope by vacuum aspiration; however, it was found to be missing once the endoscope was fully withdrawn. A second endoscopic examination found no sign of the specimen in the esophagus or oral cavity; however, a pernasal examination using a pediatric gastroscope revealed the specimen within the nasopharynx ( $\mathbf{F i g . 3}$ ). The specimen was pushed forward into the oropharynx and eventually into the cavity ( $\triangleright$ Fig.4). From there, the specimen was collected successfully. The patient was

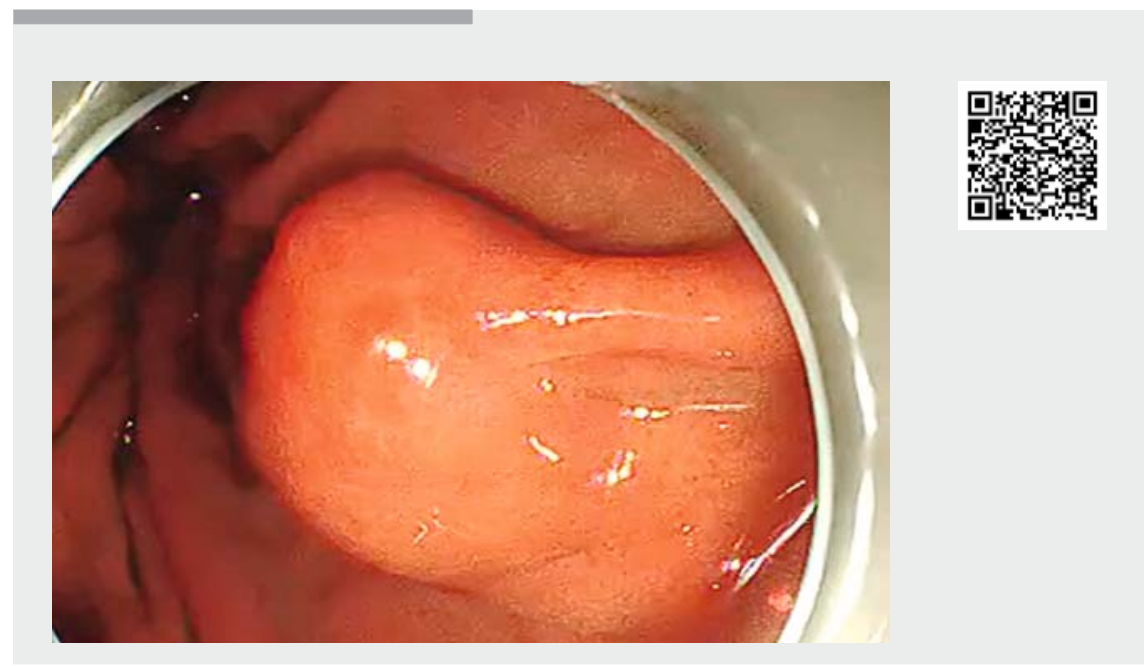

Video 1 Endoscopic submucosal excavation of a gastric stromal tumor and subsequent retrieval of the resected specimen after it had fallen into the nasopharynx.

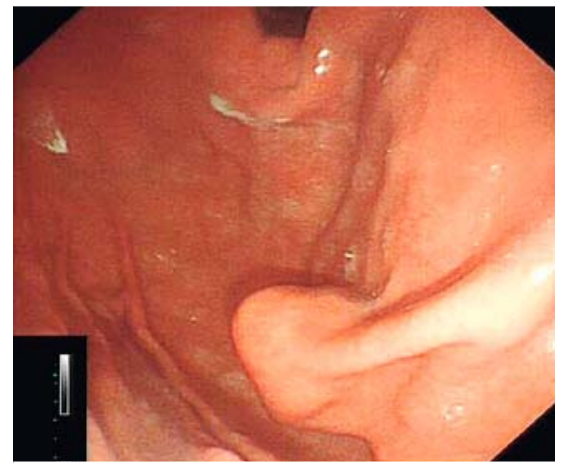

- Fig. 1 Endoscopic view showing a submucosal mass at the gastric fundus.

discharged asymptomatically 6 days later and was free of symptoms at 3-month follow-up.

This case suggests that pernasal pediatric gastroscopy could help to deal with the rare situation where an endoscopic specimen has fallen into the nasopharynx. This technique should however not be used in non-intubated patients as pushing the resection specimen into the hypopharynx could result in aspiration.

Endoscopy_UCTN_Code_CPL_1AH_2AZ

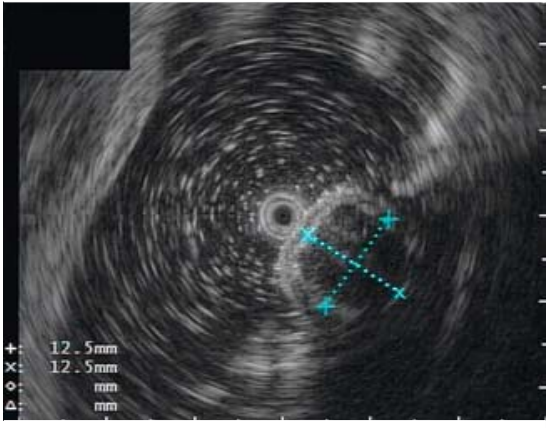

- Fig. 2 Endoscopic ultrasonography revealed a mass in the muscularis propria, measuring $12.5 \times 12.5 \mathrm{~mm}$, with homogeneous hypoechoic echogenicity.

\section{Acknowledgments}

We thank Jian He from the Department of Gastroenterology in Xiangya Hospital for the critical work on the images and video.

\section{Funding}

This work was supported by the National Natural Science Foundation of China (No. 81770584 and 81570504). 


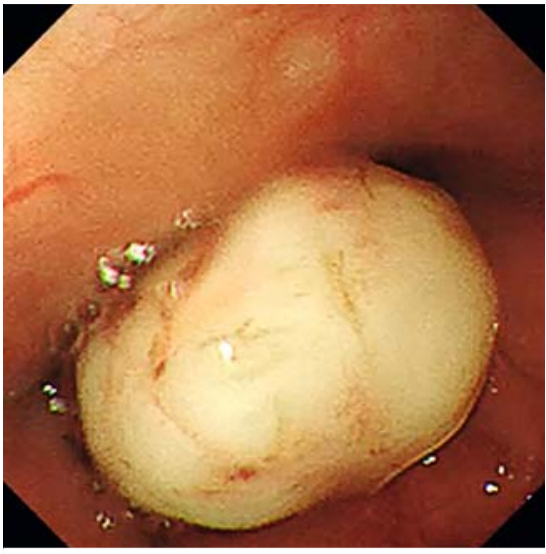

- Fig. 3 Image during pernasal examination with a pediatric gastroscope showing the specimen that had fallen into the nasopharynx.

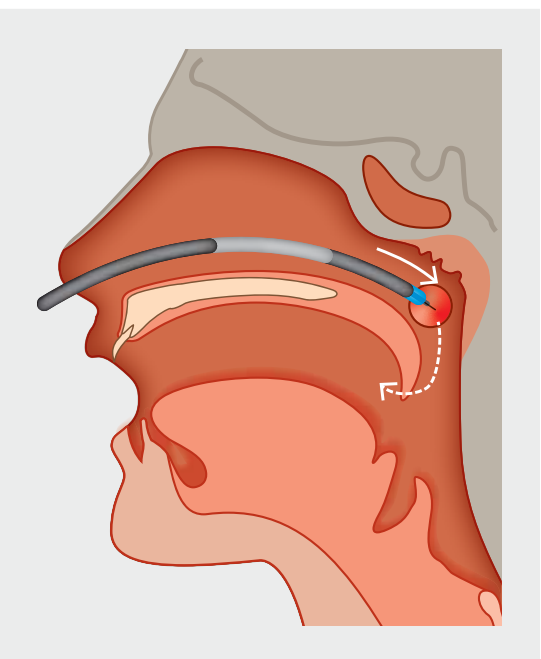

- Fig. 4 Schematic showing how the specimen was pushed forward into the oral cavity from the nasopharynx.

\section{Competing interests}

The authors declare that they have no conflict of interest.

\section{The authors}

\section{Jun $\mathrm{Yi}^{1,{ }^{*},}$, Yu Wu ${ }^{1,{ }^{*}, \text {, Honghui Chen }}{ }^{2}$, Xiaowei} Liu $^{1}$

1 Department of Gastroenterology, Xiangya Hospital, Central South University, Changsha, Hunan, China

2 Department of Gastroenterology, The Second Hospital, University of South China, Hengyang, Hunan, China

\section{Corresponding author}

\section{Xiaowei Liu, MD, PhD}

Department of Gastroenterology, Xiangya Hospital, Central South University, Changsha, Hunan 410008, China Fax: +86-731-89753268

liuxw@csu.edu.cn

\section{References}

[1] Jin XF, Gai W, Du RL et al. Multiband mucosectomy versus endoscopic submucosal dissection and endoscopic submucosal excavation for Gl submucosal tumors: short and long term follow-up. BMC Cancer 2019; 19 : 893

[2] Du C, Chai N, Linghu E et al. Treatment of cardial submucosal tumors originating from the muscularis propria layer: submucosal tunneling endoscopic resection versus endoscopic submucosal excavation. Surg Endosc 2018; 32: 4543-4551
[3] Wang S, Shen L. Efficacy of endoscopic submucosal excavation for gastrointestinal stromal tumors in the cardia. Surg Laparosc Endosc Percutan Tech 2016; 26: 493-496

\section{Bibliography}

Endoscopy 2021; 53: E15-E16

DOI 10.1055/a-1164-5977

ISSN 0013-726X

published online 29.5.2020

(c) 2020. Thieme. All rights reserved.

Georg Thieme Verlag KG, Rüdigerstraße 14, 70469 Stuttgart, Germany

\section{ENDOSCOPY E-VIDEOS}

https://eref.thieme.de/e-videos

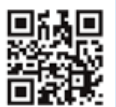

Endoscopy E-Videos is a free access online section, reporting on interesting cases and new

techniques in gastroenterological endoscopy. All papers include a high quality video and all contributions are freely accessible online.

This section has its own submission website at

https://mc.manuscriptcentral.com/e-videos 